\title{
CYP17 Lyase Inhibitor ASN001
}

National Cancer Institute

\section{Source}

National Cancer Institute. CYP17 Lyase Inhibitor ASN001. NCI Thesaurus. Code C120310.

An orally available non-steroidal, lyase-selective inhibitor of the steroid 17-alphahydroxylase/C17,20 lyase (CYP17A1 or CYP17), with potential anti-androgenic and antineoplastic activities. Upon oral administration, CYP17 lyase inhibitor ASN001 selectively binds to and inhibits the lyase activity of CYP17A1 in both the testes and adrenal glands, resulting in a significant reduction in androgen production to castraterange levels. This may both decrease androgen-dependent growth signaling and inhibit the proliferation of androgen-dependent tumor cells. The cytochrome P450 enzyme CYP17A1, which is localized to the endoplasmic reticulum, exhibits both 17alphahydroxylase and 17,20-lyase activities; it plays a key role in the steroidogenic pathway. The selective inhibition of CYP17A1 lyase activity by ASN001 prevents the increased synthesis of mineralocorticoids that is normally seen with non-selective CYP17 inhibitors, which also inhibit the 17-alpha-hydroxylase activity of CYP17A1. 